\title{
TanDEM-X for Large-Area Modeling of Urban Vegetation Height: Evidence from Berlin, Germany
}

\author{
Johannes Schreyer, Christian Geiß, Member, IEEE, and Tobia Lakes
}

\begin{abstract}
Large-area urban ecology studies often miss information on vertical parameters of vegetation, even though they represent important constituting properties of complex urban ecosystems. The new globally available digital elevation model (DEM) of the spaceborne TanDEM-X mission has an unprecedented spatial resolution $(12 \times 12 \mathrm{~m})$ that allows us to derive such relevant information. So far, suitable approaches using a TanDEM-X DEM for the derivation of a normalized canopy model (nCM) are largely absent. Therefore, this paper aims to obtain digital terrain models (DTMs) for the subsequent computation of two nCMs for urban-like vegetation (e.g., street trees) and forest-like vegetation (e.g., parks), respectively, in Berlin, Germany, using a TanDEM-X DEM and a vegetation mask derived from UltraCam$X$ data. Initial comparisons between morphological DTM-filter confirm the superior performance of a novel disaggregated progressive morphological filter (DPMF). For improved assessment of a DTM for urban-like vegetation, a modified DPMF and image enhancement methods were applied. For forest-like vegetation, an interpolation and a weighted DPMF approach were compared. Finally, all DTMs were used for nCM calculation. The nCM for urban-like vegetation revealed a mean height of $4.17 \mathrm{~m}$ compared to $9.61 \mathrm{~m}$ of a validation $\mathrm{nCM}$. For forest-like vegetation, the mean height for the $\mathrm{nCM}$ of the weighted filtering approach $(9.16 \mathrm{~m})$ produced the best results (validation $\mathrm{nCM}$ : $13.55 \mathrm{~m}$ ). It is concluded that an $\mathrm{nCM}$ from TanDEM-X can capture vegetation heights in their appropriate dimension, which can be beneficial for automated height-related vegetation analysis such as comparisons of vegetation carbon storage between several cities.
\end{abstract}

Index Terms-Digital elevation model (DEM), digital terrain model (DTM), morphological filters (MFs), normalized digital surface model (nDSM), Tandem-X, trees, UltraCamX, urban vegetation.

\section{INTRODUCTION}

$\mathbf{U}$ RBAN vegetation is known to positively regulate urban ecological processes through air purification, noise reduction, urban cooling, and run-off mitigation, as well as to provide aesthetic and environmental benefits that are commonly characterized as urban ecosystem services [1]. In recent

Manuscript received July 08, 2015; revised November 04, 2015; accepted December 01, 2015. Date of publication February 04, 2016; date of current version April 22, 2016. This work was supported by the German Research Foundation (DFG) as part of graduate program 1324 "Model-Based Development of Technologies for Self-Organizing Decentralized Information Systems in Disaster Management" (METRIK).

J. Schreyer and T. Lakes are with the Geoinformation Science Laboratory, Department of Geography, Humboldt-Universität zu Berlin, Berlin D-10099, Germany (e-mail: Johannes.Schreyer@geo.hu-berlin.de; Tobia.Lakes@geo.hu.berlin.de).

C. Geiß is with the German Remote Sensing Data Center, Geo-Risks, and Civil Security, German Aerospace Center (DLR), Weßling 82234, Germany (e-mail: christian.geiss@dlr.de).

Color versions of one or more of the figures in this paper are available online at http://ieeexplore.ieee.org.

Digital Object Identifier 10.1109/JSTARS.2015.2508660 years, these urban ecosystem services have been increasingly studied on an entire city- or country-level to inform ongoing debates on carbon sequestration [2], [3], air-pollution control [4], [5], and cooling effects [6]-[9]. Nevertheless, several negative urban ecosystem disservices are associated with urban vegetation, which are mainly social costs such as tree pollens that trigger allergies [10], [11], financial costs for street-tree management [12], infrastructural damages [13], or increased energy consumption due to shadowing [14].

For most urban ecosystem service and disservice assessments, comparable and area-wide height and volume information of trees and shrubs are needed. While methods on reconstructing buildings in their three dimensions are increasingly provided [15], [16], approaches used to derive up-to-date and city-wide three-dimensional information on the vegetation have only recently been explored [17], [18]. Very high-resolution remote sensing data offer great potential for deriving accurate height information on urban vegetation from optical sensors or active systems such as airborne light detection and ranging (LiDAR) [19], [20], or unmanned airborne vehicles [21], [22]. However, data availability is limited to a few cities and countries due to high data acquisition and processing costs, as well as privacy issues. To alleviate these restrictions, current developments of satellite-based sensors with global homogeneous coverage may provide new opportunities for comparable assessments on small-scale objects like urban vegetation.

In the past decades, space-borne radar systems have become an important technology for deriving structural and quantitative information on vegetation using various methods. Since the 1980s, synthetic aperture radar (SAR) data have been applied to forest canopy characterization and used to determine the vegetation-type, biomass components (stems, foliage, branches, leaf-off and -on), and canopy structure (e.g., leaf area index and leaf orientation) [23]. In contrast, interferometric SAR enables the direct measurement of forest heights using differences in the wave phases of two or more SAR images. In this manner, the Shuttle Radar Topography Mission (SRTM) produced a global digital elevation model (DEM) by deploying two different SAR systems with a spatial resolution of $90 \times 90 \mathrm{~m}$ (a refined spatial resolution of $30 \times 30 \mathrm{~m}$ was obtained for North America) [24]. Data from the TerraSAR-X add-on for Digital Elevation Measurement (TanDEM-X) mission have only recently become available; the system combines two nearly identical SAR sensors to derive a global homogeneous DEM (TDM) with an unprecedentedly high spatial resolution (horizontal: $12 \times 12 \mathrm{~m}$, vertical: $2 \mathrm{~m}$ ) [25].

To derive the height of objects that are elevated from the Earth's surface such as vegetation from a DEM, several 
methods have been developed. In general, the exact height of an object within a DEM can be estimated by removing the underlying terrain. Therefore, the original data have to be lowered toward a digital terrain model (DTM), which can be subtracted from the DEM afterward to derive a normalized digital surface model (nDSM) [26]

$$
n D S M=D E M-D T M .
$$

Particularly, for above-ground tree and bush vegetation, the term normalized canopy model (nCM) is used.

To derive surface heights from a DEM, Meng et al. [27] differentiate between directional-scanning, interpolationbased, segmentation-based, and morphology-based algorithms. Notably, initial studies with TanDEM-X DEMs have shown the potential to derive buildings' heights for the city of Izmir (Turkey) and Wuppertal (Germany) using a morphological filter (MF) approach [28], as well as for the area of Dongying (China), also utilizing a filter approach [29]. Even though these studies successfully proved the applicability for DTM derivation for built-up structures, the suitability for deriving vegetation structures in urban settings has not yet been analyzed.

This paper aims to evaluate a TanDEM-X DEM for estimating height information on urban vegetation using morphological approaches for a study area in Berlin, Germany. In the first step, established and novel MF approaches were compared to evaluate their performance on DTM derivation. Subsequently, workflows were developed and validated to derive a DTM for 1) vegetation in typical urban settings and 2) urban vegetation in settings similar to large forest areas. Afterward, a nDSM was calculated and two nCMs were extracted using additional vegetation data. Finally, results for both $\mathrm{nCMs}$ were validated.

\section{MATERIALS AND PRocessing}

\section{A. Study Area}

The study was conducted in Berlin, Germany (Fig. 1), which has an area of $\sim 892 \mathrm{~km}^{2}$. Almost $40 \%$ of this area is covered by urban vegetation, and thus represents the largest urban forest in Germany (circa $290 \mathrm{~km}^{2}$ with 438000 street trees) [30], [31]. Besides, its relevance regarding urban forest, Berlin has been selected due to the large amount of available validation data. In addition, Berlin's heterogeneous urban landscape covers different types of urban vegetation, as well as ground characteristics [27] that permit the evaluation of methods in a large variety of urban settings. In addition, this heterogeneity legitimizes testing on one area only. The approach was conducted in the administrative districts of Neukölln, Treptow, Kreuzberg and Friedrichshain, in the NE of Berlin (area: $\sim 70 \mathrm{~km}^{2}$, $\lambda 52^{\circ} 44^{\prime}-52^{\circ} 50^{\prime} \mathrm{N}, \varphi 13^{\circ} 36^{\prime}-13^{\circ} 52^{\prime} \mathrm{E}$ ) (Fig. 1). The type of vegetation varies depending on the urban structure type [32]. The predominant urban structure type in this area are residential block-edge buildings with high building density accompanied by tall street and backyard trees. Moreover, the area includes several high-rise buildings and areas with small business and industrial use, both with sporadic green structures. There are also several public green spaces that cover a large part of

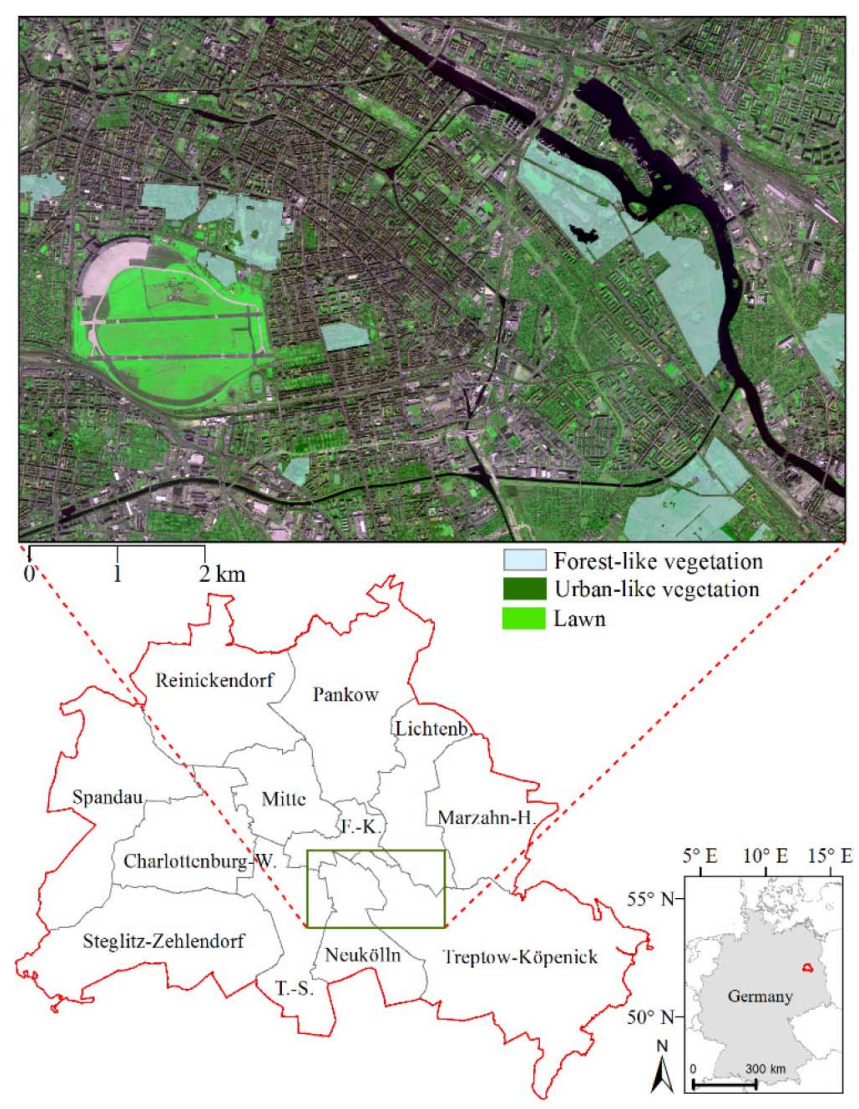

Fig. 1. Study area in Berlin, Germany. A QuickBird image depicts the study area highlighting vegetation.

the study area; $8,342 \mathrm{~km}^{2}$ of them are forested areas with mostly old and tall tree stocks in bundled or linear formation (the largest green areas are as follows: Treptower Park (park), Görlitzer Park (park), Tempelhofer Feld (park), Königsheide (commercial forest)). The terrain of the study area is mostly flat, with the exception of a glacial valley slope of $\sim 1 \mathrm{~km}$, and ranges from 29 to 68 m.a.s.l.

\section{B. Data}

The intermediate DEM (iDEM) product from the TanDEM-X mission was used in this study (see Table I and Fig. 2). Additional products for the preprocessing were as follows: 1) a biotope map including all biotope types in Berlin derived by an in situ survey and aerial image evaluation [31]; 2) a height error mask provided by the German Aerospace Center, including the standard deviation for each DEM pixel, which was derived by interferometric coherence and geometrical considerations indicating pixels with random errors [33]; 3 ) vector layers processed from an UltraCamX matrix camera, both of them containing multiple polygons covering all heights of vegetation and buildings within Berlin (for more details on the data processing, compare [34]); 4) a DTM of the Official Topographical Cartographic Information System processed with airborne LiDAR data (4 points $\left./ \mathrm{m}^{2}\right)$, which serves for validation purposes $\left(\mathrm{DTM}_{\mathrm{Val}}\right)$; and 5) a Quasigeoid for the area of Berlin containing the difference between ellipsoidal and orthometric heights (Table I; Fig. 2). 

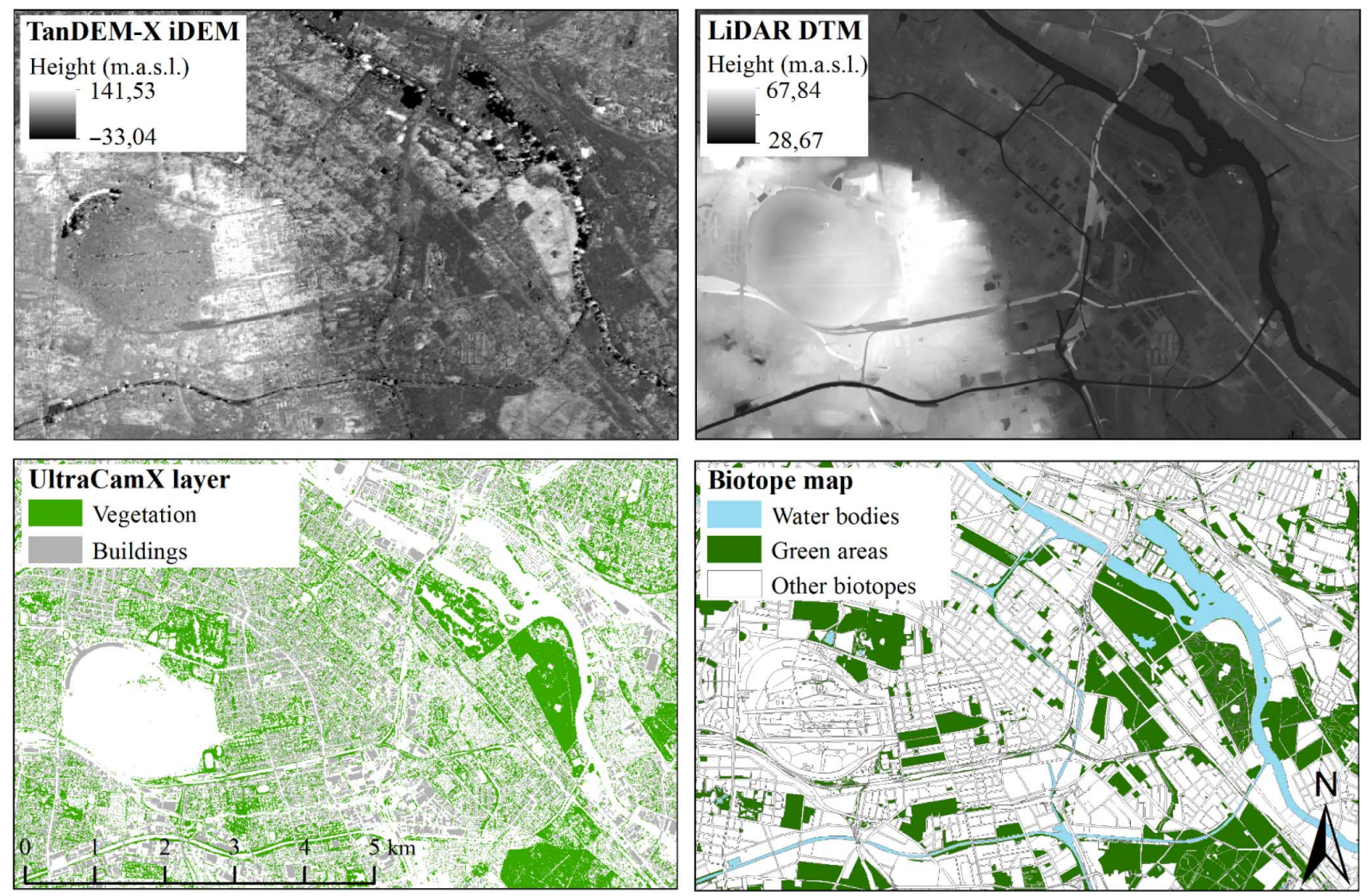

Fig. 2. Data.

\section{Preprocessing}

The original iDEM data showed layover and shadow effects in the densely built areas of Berlin since it relies on images from the first coverage. As a result, the viewing geometries from dual-/multibaseline acquisitions and multiple incident angles of additional flights are missing [33]. Moreover, the performance of the X-band backscatter is reduced over areas with surfaces such as water, and the resulting interferometric DEM contains positive and negative deviations [35]. Therefore, comprehensive preprocessing of the iDEM was undertaken with the following steps: 1) conversion from ellipsoidal to orthometric heights; 2) water masking; 3 ) including information from the height error mask; 4) detecting outliers; 5) calculating statistical errors; and 6) preprocessing of validation data. These steps are described as follows.

1) The elevation values within the iDEM represent the ellipsoidal heights relative to WGS84-G1150 [33]. Since the UltraCamX product as well as the LiDAR DTM contain orthometric heights, the iDEM was referenced accordingly using a geoid undulation model (Quaisgeoid GCG2011) [36]. This model consists of an ASCII file that contains longitude, latitude, and the height of the Quasigeoid for 299 positions across Berlin within a regular-spaced grid. Using universal kriging, the height information was interpolated to the area of Berlin to the spatial resolution of the iDEM [37]. The calculated

undulation was then subtracted from the iDEM in the study area. As a result, the mean height of $89.05 \mathrm{~m}$ of the original data was lowered to $49.74 \mathrm{~m}$ in the study area.

2) To avoid signal disturbance and false elevation values of natural and artificial waterbodies, a water mask of all waterbodies larger than $2000 \mathrm{~m}^{2}$ was derived from the biotope map. The threshold was set because small streams like drainage ditches showed no or only slight height disturbance effects in the iDEM. Finally, all areas covered by the water mask were excluded from further analyses.

3) The height error mask was used to exclude pixels with a standard deviation of larger than $3 \mathrm{~m}$ height difference.

4) Different comparative statistics [root-mean-square error (RMSE), mean error (ME), maximum, and minimum] between the iDEM and $\mathrm{DEM}_{\mathrm{Val}}$ revealed evidence for random errors and triggered outlier detection. For this study, a method developed by Breunig and Kriegel [38] was chosen to calculate a local outlier factor (LOF), which indicates by local densities for each raster row the probability of being an outlier $(\mathrm{LOF}=1$ : low probability; LOF $>1$ : high probability) by comparing a pixel to a defined neighborhood. To avoid removing the correct heights of artificial objects (e.g., single high-rise buildings, transmitter masts, power stations, or construction cranes), buildings $>50 \mathrm{~m}$ within the UltraCamX building layer were extracted for the study 
TABLE I

DATA

\begin{tabular}{|c|c|c|}
\hline Imagery/vector data & & Specifications \\
\hline $\begin{array}{l}\text { TanDEM-X products } \\
\text { Intermediate DEM } \\
\text { Height error mask }\end{array}$ & $\begin{array}{l}\text { Sensor } \\
\text { Acquired } \\
\text { Spatial resolution } \\
\text { Nominal spacing } \\
\text { Absolute horizontal } \\
\text { and vertical accuracy * }\end{array}$ & $\begin{array}{l}\text { Single-pass SAR interferometer } \\
\text { June } 2012 \text { (leaf-on) } \\
12 \times 12 \mathrm{~m} \\
0.4 \text { arc } \mathrm{s} \text { at equator } \\
<10.00 \mathrm{~m}\end{array}$ \\
\hline Quasigeoid (GCG2011) & $\begin{array}{l}\text { Sensor/data basis } \\
\text { Spatial resolution } \\
\text { Absolute vertical } \\
\text { accuracy }\end{array}$ & $\begin{array}{l}\text { Gravity measurements } \\
\text { Digital terrain models and bathymetric data } \\
\text { Geopotential models } \\
1.800 \mathrm{~m} \times 1.700 \mathrm{~m} \\
0.10-0.20 \mathrm{~m}\end{array}$ \\
\hline Biotope map & $\begin{array}{l}\text { Sensor/data basis } \\
\text { Acquired }\end{array}$ & $\begin{array}{l}\text { Various RS data (e.g., digital Orthophotos, analog CIR aerial im- } \\
\text { age slides) combined with existing vector data for Berlin } \\
2001-2012\end{array}$ \\
\hline $\begin{array}{l}\text { UltraCamX product } \\
\text { Vegetation height layer } \\
\text { Building height layer }\end{array}$ & $\begin{array}{l}\text { Sensor } \\
\text { Acquired } \\
\text { Spatial accuracy }\end{array}$ & $\begin{array}{l}\text { Matrix camera for panchromatic RGB, IR ( } 9420 \times 14430 \text { pixel) } \\
\text { August } 2010 \text { (leaf-on) } \\
0.10 \mathrm{~m}\end{array}$ \\
\hline $\begin{array}{l}\text { Airborne LiDAR product } \\
\text { DTM }\end{array}$ & $\begin{array}{l}\text { Sensor } \\
\text { Acquired } \\
\text { Spatial resolution } \\
\text { Height reference }\end{array}$ & $\begin{array}{l}\text { ALTM Gemini } \\
2007 / 08 \text { (updated June 2014) } \\
5.00 \mathrm{~m} \\
\text { German Levelling Network } 1992 \text { (DHHN92) }\end{array}$ \\
\hline
\end{tabular}

*Defined as the uncertainty in the horizontal position of a pixel with respect to the (WGS84) reference datum, caused by random and uncorrected systematic errors. The value is expressed as a circular error at a $90 \%$ confidence level [35].

area, and 111 objects $(50-100 \mathrm{~m}: 107$ objects; $>100 \mathrm{~m}$ : 4 objects) were manually compared to rows containing a $\mathrm{LOF}>1$. As a result, 70 of these 111 objects were prevented from being falsely labeled as outliers, while 45 pixels were removed as reliable ones.

5) Finally, statistical measures of the preprocessed iDEM $\left(\mathrm{DEM}_{\mathrm{TDM}}\right)$ were calculated in comparison to $\mathrm{DEM}_{\mathrm{Val}}$, which returned an RMSE of $7.47 \mathrm{~m}$, a mean absolute error (MAE) of $5.06 \mathrm{~m}$, and an ME of $-1.72 \mathrm{~m}$. The $\mathrm{DEM}_{\text {TDM }}$ could be classified as a Level 1 product using the accuracy classification system of the United States Geological Service (USGS) (Level 1: RMSE 7-15 m; Level 2: RMSE < one - half contour interval; Level 3: RMSE $<$ one - third contour interval) [39].

6) UltraCamX data were used for validation because of their high resolution $(0.10 \mathrm{~m}$ vertical and horizontal accuracy) and similar date of data acquisition. The area and height layer were rasterized into a layer containing pixels of bare earth, vegetation, and buildings (class 0: bare earth; class 1: vegetation; class 3: buildings). To accomplish this, both layers were rasterized using the grid size of $\mathrm{DEM}_{\mathrm{TDM}}$, and the relative proportions of a shape containing class 0,1 , or 2 within a single raster pixel were calculated by using bilinear interpolation. Results returned pixel values ranging between $0 \%$ and $100 \%$. All pixels containing more than $50 \%$ of class 1 or 2 were declared to be a pixel mainly containing building or vegetation. This product was created to validate the outcome of object and bare earth pixel filtering. The procedure was repeated only using the vegetation layer to derive a layer for the detection of areas of urban-like vegetation within the processed height models. In an additional step, the vegetation layer was rasterized, resulting in a raster layer attributed to the height values of the vector shape. This raster layer was involved in the workflow as a validation height model for accuracy assessment $\left(\mathrm{nCM}_{\mathrm{Val}}\right)$. The biotope map for Berlin includes shapes of public green areas, of which all areas greater than $65000 \mathrm{~m}^{2}$; were extracted to identify the areas of forest-like vegetation. Overall, 15 shapes met this condition.

Finally, all data were resampled to the spatial resolution of DEM $_{\text {TDM }}$ and assigned to the same reference system (UTM, Zone 33 and WGS84 ellipsoid).

\section{Methods}

\section{A. Overview}

The methodology for assessing a $\mathrm{nCM}$ from $\mathrm{DEM}_{\mathrm{TDM}}$ in urban areas is described below (Fig. 3). First, three established MF approaches were compared, and subsequently, a disaggregated filter approach was chosen because of best results. However, the outcome illustrated the need to differentiate between two types of vegetation in subsequent steps: Urbanlike vegetation, defined as single or small groups of trees located in streets, backyards or close to streams, mostly in close proximity to build objects; Forest-like vegetation, characterized by densely vegetated large green areas (parks, commercial forests, allotments, and cemeteries larger than $65000 \mathrm{~m}^{2}$ ). Both vegetation types are shown in Fig. 1. 1) For urban-like vegetation, a multistep procedure using DPMF aimed to distinguish objects from bare earth pixels, and the latter were then used to interpolate a DTM (DTM $\left.\mathrm{DLV}_{\mathrm{UL}}\right)$. 2) For forest-like vegetation, an interpolation and a novel weighted DPMF were compared, including the previously produced $\mathrm{DTM}_{\mathrm{ULV}}$ from step 1). Next, two DTMs for forest-like vegetation $\left(\mathrm{DTM}_{\mathrm{FLV} \_\mathrm{I}}\right.$ and $\left.\mathrm{DTM}_{\mathrm{FLV} \_\mathrm{II}}\right)$ were interpolated, and three nCMs were calculated for both 


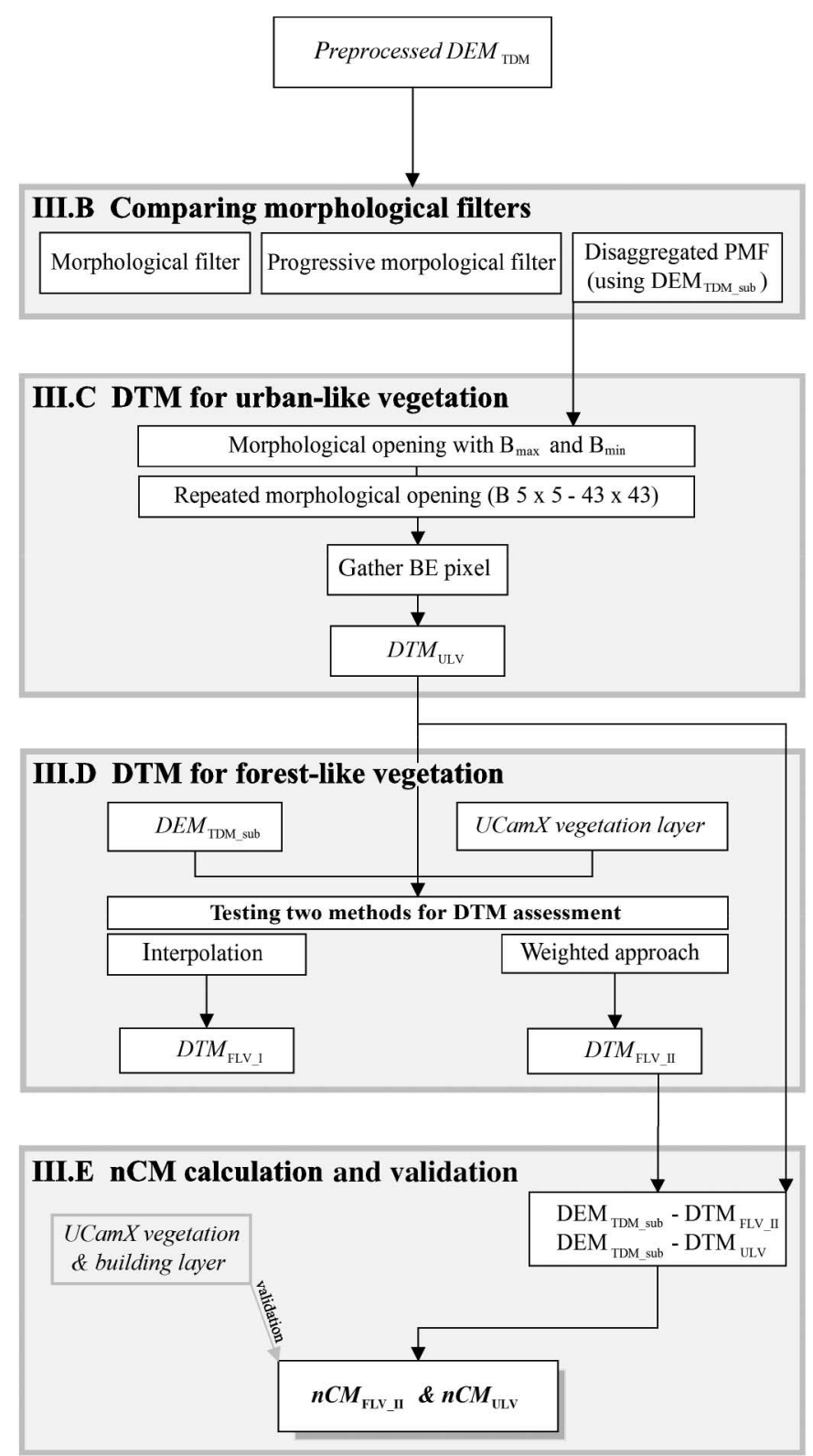

Fig. 3. Workflow of the entire procedure. Each shaded box matches Section III.

vegetation types (urban-like vegetation: $\mathrm{nCM}_{\mathrm{ULV}}$; forest-like vegetation: $\mathrm{nCM}_{\mathrm{FLV} \_}$and $\left.\mathrm{nCM}_{\mathrm{FLV} \_\mathrm{II}}\right)$.

The detection of vegetation pixels was validated using the UltraCamX vegetation layer, and the vertical accuracy of all DTMs and nCMs was assessed using $\mathrm{DTM}_{\mathrm{Val}}$ and $\mathrm{nDSM}_{\mathrm{Val}}$.

The entire workflow was conducted in the statistical programming software R (Version 3.1.2; main packages: "Raster," "mmand," "rgdal") [40], with the exception of the local Sigma filter, which was applied in ENVI (Version 5.1) [41]. The authors can provide the $\mathrm{R}$ code upon request.

\section{B. Comparing $M F$}

In order to derive a DTM from a DEM, several MFs had been previously developed and applied on the subject of urban terrain filtering, mainly using very high-resolution data [27]. As the main principle, objects like trees can be distinguished by their height differences to surrounding ground pixels within a specified neighborhood. Similar to Geiß et al. [28] a simple MF and a progressive MF (PMF) were applied. Additionally, a filter was developed that uses a disaggregated DEM for a subsequent PMF procedure [disaggregated PMF (DPMF)]. In the following, the three filtering techniques of MF, PMF, and DPMF are briefly explained.

1) Morphological Filter: When using the MF, the input DEM is arranged by applying a structuring element $B$ in which a pixel value is compared and altered in accordance to the values of its neighborhood following the provided rules. These rules consist of two basic operators, namely, erosion and dilation. In terms of gray-scale morphology, the minimum [erosion, (2)] or maximum [dilation, (3)] is searched within $B$ of a continuous elevation set with cells $\mathrm{p}(\mathrm{x}, \mathrm{y}, \mathrm{z})$ [42], [43].

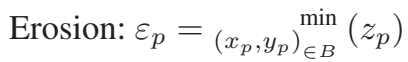

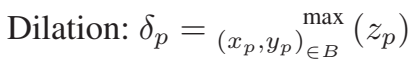

By sequentially applying a dilation to a previously eroded surface, an opening operation is conducted:

$$
\text { Opening } \gamma_{p}=\delta_{p} \circ \varepsilon_{p}\left(z_{p}\right) \text {. }
$$

Concerning the derivation of a $\mathrm{nDSM}$, the opening operation is of particular importance; its performance on an elevation set with urban objects such as trees or buildings will lower all elevations to the minimum pixel within $B$, which is ideally a BE pixel and subsequently ensures coherent structure differences with an affiliated dilation. The constant increase of the size of $B$ from the minimum $\left(B_{\min }\right)$ to the maximum $\left(B_{\max }\right)$ is intended to eliminate small to large urban objects. Usually, an overflattening of terrain is associated with the simple MF (compare [27] and [28]), since objects, but also small natural or artificial ground elevations, are reduced to the minimum value within the structuring element. By this effect, errors are more likely to occur in steep terrain. In this study, $B_{\max }$ was determined by the largest building from the Ultracam building layer to avoid the erosion of natural elevations such as the slope of the glacial valley. By these conditions, an MF with $B_{\max }$ of $15 \times 15$ pixels was performed fitted to the buildings with the largest square area, namely, several building supply stores and factories $\left(20000-30000 \mathrm{~m}^{2}\right)$.

2) Progressive Morphological Filter: In contrast to the MF filter, the PMF approach attempts to isolate bare earth (BE) and object (OBJ) pixels by iteratively detecting OBJ pixels. The remaining pixels are labeled as BE pixels and subsequently got interpolated to a DTM. More specifically, the DEM is subject to an opening operation and subtracted from the original DEM to establish a height difference $(d h)$ at pixel $p\left(d h_{p}\right)$. Afterward, OBJ and BE pixels are identified by applying an elevation difference threshold $(\theta)$ on $d h_{p}$ according to the following rules [43]:

$$
\mathrm{BE} \text { pixel }=d h_{p}<\theta, \quad \text { OBJ pixel }=d h_{p}>\theta .
$$

The values for $B$ and the elevation difference threshold constantly change with every filter step, and the process is stopped 
when $B_{\max }$ is reached, which exceeds a specific size related to the largest object in the study area. In this manner, small objects can be detected and changes in terrain height are preserved by subsequently removing OBJ pixels above the elevationdifference threshold only [43]. For this study, a PMF was conducted on $\mathrm{DEM}_{\mathrm{TDM}}$ using the same $B_{\min }$ and $B_{\max }$ as for the MF approach. Adjusting the suggestion from Zhang et al. [43] to this case study, an elevation-difference threshold of $0.2 \mathrm{~m}$ was chosen based on the vegetation-specific assumption that small trees and tall bushes can be captured.

3) Disaggregated Progressive Morphological Filter: Third, a disaggregated approach was tested, which aims at internalizing the advantages of the PMF applied to a DEM with a higher spatial resolution of $4 \times 4 \mathrm{~m}$. Therefore, each DEM pixel was disaggregated with a divisor of 3 and locally interpolated by three-point linear interpolation [44]. As a result, each pixel was divided into nine subcells (DEM TDM_sub $_{\text {_ }}$ ), and $B_{\max }$ was calculated by multiplying $B_{\max }$ of PMF $(15 \times 15)$ with the value " 3 " $(45 \times 45)$. In addition, the DPMF approach was tested with a square and focal shape of $B$ on DEM $_{\text {TDM_sub }}$ to explicitly address the organic structures of trees and vegetation.

The three approaches were applied to the entire study area, and the identified BE pixels in the PMF and DPMF were interpolated by the inverse distance-weighted (IDW) method [45] to calculate three preliminary DTMs.

\section{DTM Generation for Urban-Like Vegetation: Disaggregated Filtering}

After comparing the three MFs, the DPMF was chosen to assess urban- and forest-like vegetation due to its best performance (see Section VI-A). In the next step, the DPMF was improved for the final calculation of $\mathrm{DTM}_{\mathrm{ULV}}$. For this purpose, the forest-like vegetation patches were masked out of the preprocessed DEM. Overall, the entire study area consists of 4444308 pixels, of which $13.45 \%$ were masked to be not available (NA) as a result of preprocessing and masking of forest-like vegetation.

First, DEM $_{\text {TDM_sub }}$ was opened with $B_{\max }(45 \times 45)$, and a threshold with a restrictive value (8.00) was applied to gain BE pixels that could be considered reliable in the first step. Within this filter step, every nonnatural elevation was decreased to the surrounding BE pixels while overestimating the amount of OBJ pixels that appear as coherent agglomerations (type II error). In order to prevent errors of omission for small vegetation components, the first filter size of $3 \times 3$ was applied with a small threshold of $0.4 \mathrm{~m}$, but still remained relatively high to ensure avoiding errors of commission. For the remaining pixels, the process of DPMF was repeated similar to that in Section III-B, but using a slightly larger threshold $(0.8,1.6,2.4, \ldots, 16)$ to gain reliable OBJ pixels. Ideally, small single trees or groups were identified with $B_{\min }$, and high vegetation stocks such as street avenues were iteratively removed in the following filter steps up to $B_{\max }=43 \times 43$.

The OBJ pixels of all filter steps $(3 \times 3-43 \times 43)$ with the exception of $B_{\max }$ were gathered and used to mask the preprocessed DEM. The remaining BE pixels were grouped in one raster and interpolated to a set of height-attributed BE pixels apart from withdrawn pixels from preprocessing. The resulting DTM was subtracted from DEM TDM_sub $_{\text {to }}$ gain a preliminary DSM for urban-like vegetation, which was subsequently subject to local Sigma filtering to enhance object areas by an edge detection [46]. Since Geiß et al. [28] were able to improve the delineation of buildings by a Lee-Sigma edge-detection algorithm, this step also aimed to improve the boundaries of vegetated areas. Within a $3 \times 3$ structuring element, the local standard deviation was computed for each pixel and its neighborhood, and pixels were classified as valid/nonvalid in case of their deviation of the neighboring pixel. If they met the condition of being valid, each pixel value was replaced by the mean value of all pixels within the structuring element [46]. This adaptive filtering process was carried out to reconstruct objects based on reliable OBJ pixels that were gathered by using a high elevation-difference threshold from $5 \times 5-43 \times 43$. The identified OBJ pixels were subsetted of the amount of previously gathered BE pixels, and a DTM was again interpolated. Afterward, a mean filter $(3 \times 3)$ was used to offset small variations within the final DTM $\mathrm{ULV}_{\mathrm{UV}}$. For accuracy assessment, OBJ and BE pixels within vegetated areas had to be identified. For that, the rasterized binary vegetation layer of the UltraCAMX data was included, and all pixels with $>50 \%$ of class vegetation were used to identify the relevant $\mathrm{BE}$ and $\mathrm{OBJ}$ pixels.

\section{DTM Generation for Forest-Like Vegetation: An Interpolation and Weighted Filter Approach}

As explained in Section III-A, a different workflow for forest-like vegetation areas had to be conducted, since the absence or scarcity of BE pixels in dense vegetation structures of areas such as public parks hampered their morphological opening. However, values of $B$ were not adjusted according to the largest forest-like vegetation patch, since natural elevations such as the slope of the glacial valley would be identified as OBJ pixels and thus would be erased. To cope with this problem, two approaches were tested on $\mathrm{DEM}_{\mathrm{TDM}_{\text {_sub }}}$ including the DTM for urban-like vegetation.

The first approach aimed to interpolate the identified BE pixels in the surrounding of each large vegetation patch. First, the 15 forest-like areas were used to mask the previously derived $\mathrm{DTM}_{\mathrm{ULV}}$. The resulting gaps were subject to an IDW interpolation.

The second approach relied on fitting structuring elements $(B)$ to the specific size of each forest-like vegetation patch within a weighted DPMF procedure. In the first step, the 15 areas of forest-like vegetation were extracted from the preprocessed and disaggregated DEM (DEM $\mathrm{TDM}_{\mathrm{T}}$ sub $)$ and added to the previously produced DTM for urban-like vegetation $\left(\mathrm{DTM}_{\mathrm{ULV}}\right)$. Second, each of the 15 biotope shapes was buffered by $150 \mathrm{~m}$, and the outcome was used to crop the previously merged rasters. As a result of these steps, the product contained only forest-like vegetation of the $\mathrm{DEM}_{\mathrm{TDM}}$ ssub surrounded by an adjacent $150 \mathrm{~m}$ buffer of DTM $\mathrm{ULV}_{\mathrm{LV}}$. Third, the necessary size of $B$ for the largest vegetation patch was 
calculated $(235 \times 235)$ to gain an initial size for the filter process.

By relating the size of the 14 remaining vegetation patches to that of the largest, a relative weighting factor was calculated and multiplied with $B$ for the largest vegetation patch to gain the single patch-specific size of $B$. Finally, the single weights were used to conduct the weighted DPMF. The corresponding threshold for DPMF ranged between 7 and 10, and increased with an augmenting size of $B$. As a result, a DTM for the forestlike vegetation was achieved.

\section{E. nCM Calculation and Validation}

In the final processing step for the nCM, the derived DTMs for urban- and forest-like vegetation were normalized using the preprocessed and disaggregated DEM. In greater detail, nDSMs for both vegetation types were calculated by subtracting $\mathrm{DTM}_{\mathrm{FLV} \_}$, DTM $\mathrm{FLV}_{-} \mathrm{II}$, and $\mathrm{DTM}_{\mathrm{ULV}}$ from the respective areas of $\mathrm{DEM}_{\mathrm{TDM}}$ _sub. Within the resulting $\mathrm{nDSM}$, regions with urban-like vegetation were identified by the UltraCamX vegetation layer and regions with forest-like vegetation by the use of the biotope shapes for green areas. This working step produced the final nCMs for both vegetation types (ULV : $\mathrm{nCM}_{\mathrm{ULV}} ; \mathrm{FLV}: \mathrm{nCM}_{\mathrm{FLV} \_}, \mathrm{FLV}: \mathrm{nCM}_{\mathrm{FLV} \_\mathrm{II}}$ ).

Horizontally, the PMF and DPMF output were validated using the raster layer with the thematic classes of bare earth, vegetation, and buildings. A confusion matrix was created and the overall accuracy (OVA) and Cohen's kappa coefficient were calculated for areas with urban- and forest-like vegetation [47]. Vertically, the accuracies of all DTMs and nCMs were assessed by calculating several accuracy metrics (MAE, $\mathrm{ME}$, and RMSE), and statistical metrics (minimum, maximum, and mean elevation) compared to the specific areas in the validation DTMs and respective nCMs separately for urban- and forest-like vegetation. For the validation of the disaggregated approaches, all validation data were resampled to $4 \times 4 \mathrm{~m}$.

\section{RESUlTS}

\section{A. Comparing $M F s$}

The performance of the different MF approaches clearly differed when assessing the DTM and the DEM for urbanand forest-like vegetation (see Table II). All three approaches operated much better for urban-like vegetation than for forestlike patches, which highlighted the need for differentiated approaches according to the specific vegetation-type. As expected, the MF produced the highest inaccuracies, which was likely caused by erosion of hilly terrain. Even though both progressive approaches varied only slightly, the DPMF performed better. As a result, the DPMF was chosen for DTM assessment in the subsequent steps.

\section{B. DTM and $n C M$ for the Urban-Like Vegetation}

OVA when including the classes of bare earth, vegetation, and buildings was calculated to be 0.8 , and Cohen's kappa coefficient was 0.71. The results of the DPMF could be improved by additionally using the local sigma and mean filter, which is expressed in lowered statistical deviations with respect to $\mathrm{DTM}_{\text {Val }}$ (as can be seen from ME, MAE, and RMSE in Table III). The DTM $\mathrm{ULV}_{\mathrm{V}}$ was compared to the mean elevation of $\mathrm{DTM}_{\text {Val }}$, and an underestimation by $4.01 \mathrm{~m}$ was reported (Table III).

To provide greater detail on the processing for $\mathrm{DTM}_{\mathrm{ULV}}$, $36.62 \%$ of the cells were filtered as $\mathrm{OBJ}$ and $63.38 \%$ as $\mathrm{BE}$ pixels $\left(\mathrm{DTM}_{\mathrm{Val}}: 73.18 \%\right.$ OBJ pixels).

More precisely, $65.33 \%$ of $\mathrm{BE}$ pixels were identified in the very first step using $B_{\max }$ of $45 \times 45$ with a low elevationdifference threshold, and an excessive number (109.5\%) were extracted in the following DPMF steps $(3 \times 3$ to $43 \times 43)$. After morphological filtering, the $\mathrm{BE}$ pixel proportion of $109.5 \%$ was reduced by enhancing the boundaries of OBJ pixels by the local Sigma filter within a preliminary $D_{S M_{U L V}}$ to the final amount.

The results for $\mathrm{DEM}_{\mathrm{TDM}}$ _sub, the unsmoothed (DTM $M_{\text {ULV_raw }}$ ), and smoothed DTM (DTM $\left.M_{U L V}\right)$ are illustrated for a transect in Fig. 4, which shows the offset between

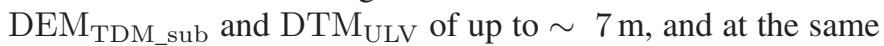
time, the preservation of the elevation basis.

The accuracy assessment of the elevations in $\mathrm{nCM}_{\mathrm{ULV}}$ revealed that the minimum elevation height was very similar $\left(\mathrm{nCM}_{\mathrm{ULV}}: 1.98 \mathrm{~m}, \mathrm{nCM}_{\mathrm{Val}}: 2.14 \mathrm{~m}\right)$, the mean elevation height within $\mathrm{nCM}_{\mathrm{ULV}}$ was $4.35 \mathrm{~m}$, which is less than half of the mean elevation within $\mathrm{nCM}_{\text {Val }}(9.61 \mathrm{~m})$ (see Table III). Both maximum height values are too high to represent tree tops, but can be attributed to false classifications of roof top vegetation in the UltraCamX vegetation layer. Fig. 5 shows a subset of $\mathrm{nCM}_{\mathrm{ULV}}$ in the area of Neukölln, Berlin, of which artificial areas were completely excluded and only the height of single vegetation structures remained.

\section{DTM and nCM for Forest-Like Vegetation}

The 15 masked-out forest-like vegetation patches included $7.13 \%$ of the pixels not classified to be water or NA in the entire study area. During the interpolation process, these pixels were interpolated using the IDW method, which resulted in the first DTM (DTM $\left.\mathrm{FLV}_{-}\right)$for the forested areas. For the second DTM for forested areas (DTM $\left.\mathrm{FLV}_{-} \mathrm{II}\right), \mathrm{BE}$ and vegetation pixels were first separated within the weighted DPMF approach to apply an interpolation method afterward (see Fig. 6). The OVA for the forest-like areas was calculated to be 0.83 , and the Cohen's kappa coefficient was 0.74. Subsequently, both DTMs were statistically compared to $\mathrm{nCM}_{\text {Val }}$ shaped to the single 15 patches. All statistical measures demonstrated better performance compared to the preliminary DTM for forest-like areas during the comparative filtering (Tables II and IV). As shown in Table IV, MAE, ME, and RMSE measured for the $\mathrm{DTM}_{\mathrm{FLV} \_ \text {II }}$ approach were lower than those of DTM $\mathrm{FLV}_{-}$. Additionally, the mean elevation of $\operatorname{DTM}_{\text {FLV_I }}(40.37 \mathrm{~m})$ deviated more from DTM $_{\text {Val }}(37.19 \mathrm{~m})$ than the result of $\mathrm{DTM}_{\mathrm{FLV}}$ II $(40.37 \mathrm{~m})$. The validation of both $\mathrm{nCM}$ for forestlike vegetation confirmed the slightly better performance of the weighted DPMF approach; MAE, ME, and RMSE were 
TABLE II

Accuracies of the DTMs Derived From the Morphological Filtering for Urban-Like Vegetation (ULV) And Forest-Like VEGETATION (FLV)

\begin{tabular}{|c|c|c|c|c|c|c|c|}
\hline $\begin{array}{c}\text { Filter } \\
\text { approach }\end{array}$ & $\begin{array}{l}\text { Vegetation } \\
\text { type }\end{array}$ & $\mathrm{B}_{\min } / \mathrm{B}_{\max }$ & $\begin{array}{c}\text { Nr. of } \\
\text { iterations }\end{array}$ & $\theta$ & MAE & ME & RMSE \\
\hline MF & $\begin{array}{l}\text { ULV } \\
\text { FLV }\end{array}$ & $3 \times 3 / 15 \times 15$ & $2,3 \ldots .7$ & - & $\begin{array}{c}6.90 \\
10.80\end{array}$ & $\begin{array}{c}7.20 \\
-10.67 \\
\end{array}$ & $\begin{array}{c}8.22 \\
16.54 \\
\end{array}$ \\
\hline PMF & $\begin{array}{l}\text { ULV } \\
\text { FLV }\end{array}$ & $3 \times 3 / 15 \times 15$ & $2,3 \ldots .7$ & $1.8,2.0, \ldots, 3.2$ & $\begin{array}{c}6.10 \\
11.20\end{array}$ & $\begin{array}{c}5.95 \\
11.60\end{array}$ & $\begin{array}{c}6.35 \\
14.20\end{array}$ \\
\hline DPMF & $\begin{array}{l}\text { ULV } \\
\text { FLV }\end{array}$ & $3 \times 3 / 45 \times 45$ & $2,3 \ldots . .21$ & $0.6,1.2, \ldots, 12.6$ & $\begin{array}{l}5.67 \\
9.56 \\
\end{array}$ & $\begin{array}{c}5.88 \\
10.20 \\
\end{array}$ & $\begin{array}{c}6.22 \\
13.90\end{array}$ \\
\hline
\end{tabular}

TABLE III

DESCRIPTIVE STATISTICS AND RMSE FOR ULV Height MODElS

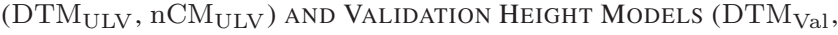
$\mathrm{nCM}_{\text {Val }}$

\begin{tabular}{c|c|c|c|c|c|c}
\hline Height & Mean & Min. & Max. & MAE & ME & RMSE \\
\hline \multicolumn{7}{c}{ DTM } \\
\hline \hline DTM $_{\text {ULV }}$ & 43.64 & 22.24 & 72.11 & 2.24 & 2.20 & 3.92 \\
\hline DTM $_{\text {Val }}$ & 38.63 & 29.27 & 67.78 & - & - & - \\
\hline \hline \multicolumn{7}{c}{ nCM } \\
\hline \hline nCM $_{\text {ULV }}$ & 4.35 & 1.98 & 44.86 & 7.53 & 7.00 & 8.85 \\
\hline nCM $_{\text {Val }}$ & 9.61 & 2.14 & 44.80 & - & - & - \\
\hline
\end{tabular}

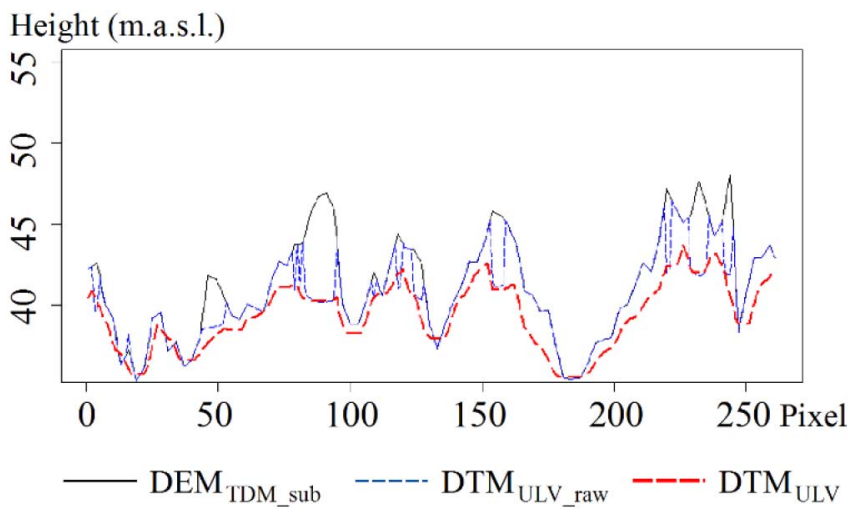

Fig. 4. Transect of $\mathrm{DEM}_{\mathrm{TDM}}$, unsmoothed (DTMULV_raw $)$, and meanfiltered DTM $\left(\mathrm{DTM}_{\mathrm{ULV}}\right)$ on a range of 250 pixel $(=1000 \mathrm{~m})$.

lower and the mean, maximum, and minimum elevation deviated less from the validation $\mathrm{nCM}$ (see Table IV). Similar to the urban-like vegetation data, the mean height of both $\mathrm{nCM}$ for forest-like vegetation varied $\sim 5$ to $6 \mathrm{~m}$ from the validation data $\left(\mathrm{nCM}_{\text {Val }}: 13.55 \mathrm{~m} ; \mathrm{nCM}_{\mathrm{FLV} \_\mathrm{II}}: 9.16 \mathrm{~m} ; \mathrm{nCM}_{\mathrm{FLV} \_} \mathrm{I}\right.$ $7.83 \mathrm{~m})$.

\section{DISCUSSION}

The present study reveals the applicability and potential of using TanDEM-X DEM for height assessment of common urban vegetation using morphological approaches. Height was estimated using $\mathrm{nCMs}$ for vegetation in urban-like conditions (mainly street and backyard trees) and forest-like conditions (mainly parks and commercial forests $>65000 \mathrm{~m}^{2}$ ). For urbanlike vegetation, the mean height of the $\mathrm{nCM}$ resulting from the improved DPMF was calculated to be $4.35 \mathrm{~m}$; this was approximately one-half of the mean height of the validation nCM $(9.61 \mathrm{~m})$. For forest-like vegetation, a weighted filter approach produced a more accurate height model than an interpolation method, resulting in a mean height of $9.16 \mathrm{~m}$ (validation nCM: $13.55 \mathrm{~m}$ ). Because of the consecutive character of the entire workflow, the accuracy of the final nCMs strongly depended on the outcome of the single-methodological steps, namely, 1) comparison of two existing and a new MF for DTM derivation; 2) DTM derivation for urban-like vegetation; 3) DTM derivation for forest-like vegetation; and 4) calculation of nCMs.

The first step aimed to compare the performances of a simple MF, PMF, and a novel DPMF for deriving a DTM on all settings of urban vegetation. Similar to earlier studies on building objects in urban areas [28], [43], the simple MF produced the greatest deviations and cannot be recommended for the purpose of urban vegetation height estimation using a DEM with the presented spatial resolution, even for less-hilly terrain. In comparison to the PMF, the DPMF was found to produce a more accurate DTM and nCMs for both vegetation types related to the validation DTM (RMSE preliminary DTM for urban-like vegetation: $6.22 \mathrm{~m}$; RMSE preliminary DTM for forest-like vegetation: $13.90 \mathrm{~m}$ ). This outcome confirms the proposed assumption that bare earth and object pixels are classified more accurate as a result of higher spatial resolution. Moreover, this methodological step displayed the need of an individual approach for both forest- and urban-like vegetation, respectively.

In the second methodological step, the most appropriate filter of DTM assessment was attempted to be improved for urban-like vegetation. As a result of a modified DPMF and image-enhancement methods (Local Sigma filtering, mean filter), deviations to $\mathrm{DTM}_{\text {Val }}$ were reduced for $\mathrm{DTM}_{\mathrm{ULV}}$. Since benchmark accuracies and results from other studies are largely absent within this novel application context, the outcome of the classification of bare earth and object pixels is based on a general evaluation of accuracy. In this manner, the corresponding OVA $(0.81)$ and kappa coefficient $(0.65)$ for both thematic classes can be evaluated as "moderate" or "good" according to the categorization provided by Czaplewski [48]. However, the result still displays a large offset compared to the validation DTM, which can be due to several reasons. The higher mean elevation of $\mathrm{DTM}_{\mathrm{ULV}}$ compared to $\mathrm{DTM}_{\mathrm{Val}}$ indicates an error of omission resulting from incomplete detection of objects during the DPMF. The local Sigma filter does not seem to perform well on vegetation components, likely because areas of 


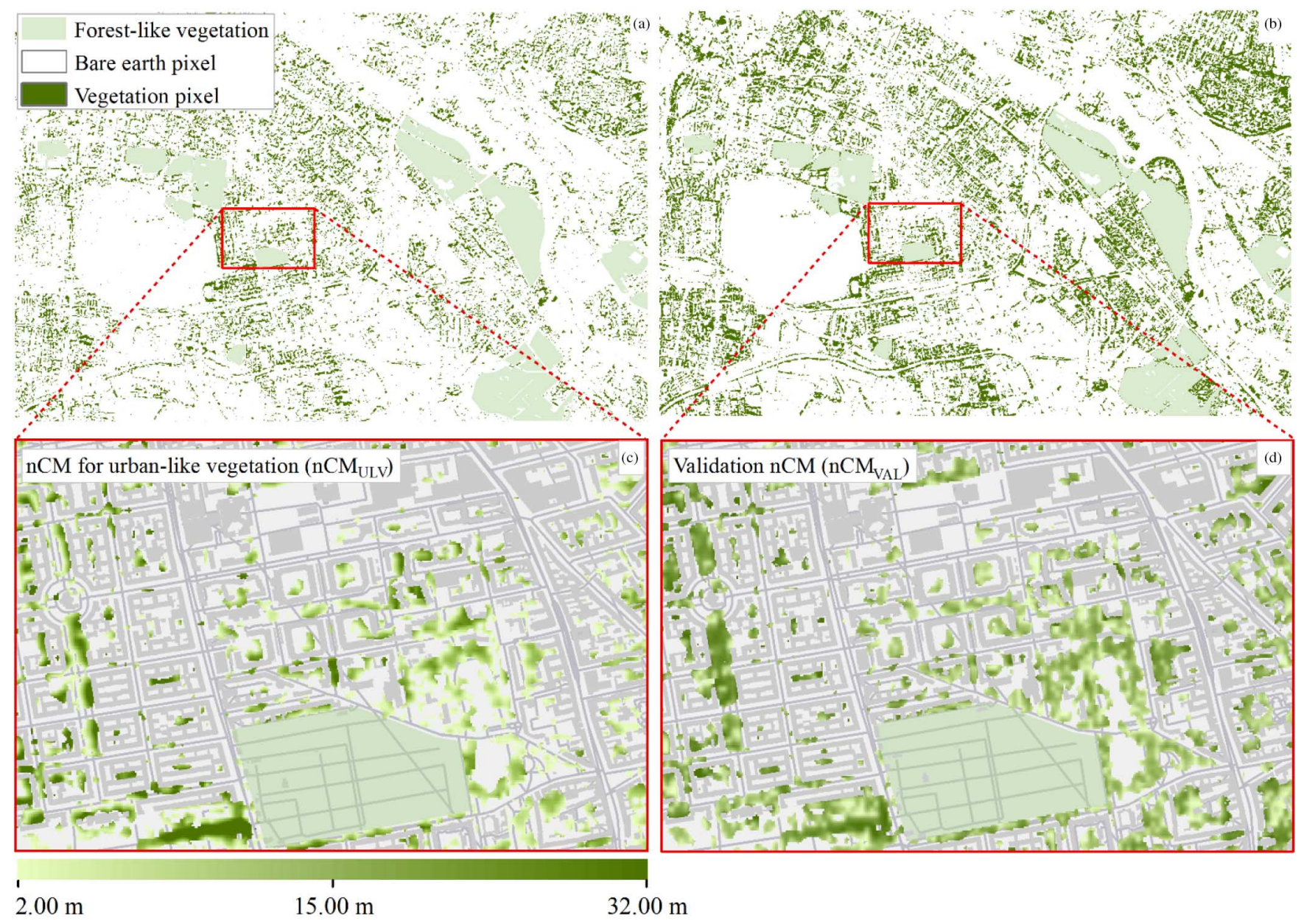

Fig. 5. Results of (a) DPMF-filtering in comparison to (b) UltraCam vegetation layer; and (c) nCM for urban-like vegetation in comparison to (d) validation nCM.

the same standard variation only rebuild a small part of a pixel conglomeration belonging to vegetation. Improvements in the differentiation of bare earth and object pixels may be achieved by using object-based image analysis techniques to delineate vegetation and artificial objects from terrain more precisely. Many segmentation approaches have been applied for vegetation and crown delineation [49], [50] using high-resolution data, and some of these methods may be helpful. For example, a watershed delineation could be suitable for separating homogeneous and heterogeneous segments of elevation that indicate terrain and objects as an additional source of information before or after the DPMF [51], [52].

For forest-like vegetation, two different methods to create DTMs were compared. The study had to address the problem of forest-like vegetation areas, in which the amount of bare earth pixels was reduced and the application of a corresponding large size of $B$ would erase surrounding natural elevations. Both proposed approaches (interpolation and weighted DPMF) were able to highly improve the preliminary DTM for forest-like vegetation presented in Section III-B. However, as a result of weighted DPMF, DTM $\mathrm{FLV}_{\text {_II }}$ was slightly better since it performed in conjunction with a few scattered bare earth pixels that were completely missing in the case of DTM $_{\mathrm{FLV}}$ I. Since incorrect DTM heights for urban-like conditions are also reflected in the DTM for forest-like vegetation, an improvement of the DTM $\mathrm{ULV}_{\mathrm{LV}}$ would likely increase the quality of results for both approaches for forest-like vegetation. Similar to urban-like vegetation, the ability to compare both DTMs to the outcome quality of other studies is limited because few studies deal with DTM filtering in dense forested areas using mathematical morphology and low-resolution raster data. Liu et al. [53] used a sequence of morphological operators combined with segmentation to derive a DTM using SRTM data for two forest areas. The authors were able to reduce the RMSE from $23.58 \mathrm{~m}$ to $12.59 \mathrm{~m}$ and $14.32 \mathrm{~m}$ to $7.55 \mathrm{~m}$, respectively, using the outcome compared to a national elevation dataset (NED). Against this background, the qualities of the results for the present study are comprehensible $\left(\right.$ RMSE DTM $_{\mathrm{FLV}_{-} \mathrm{I}}: 5.74 \mathrm{~m}, \mathrm{RMSE}_{\mathrm{DTM}} \mathrm{FLV}_{-\mathrm{II}}$ : $4.22 \mathrm{~m})$.

Finally, statistical measures for all produced nCMs and the validation $\mathrm{nCM}$ were calculated (Tables III and IV). The average mean elevation of all final nCMs deviated $\sim 5$ to $6 \mathrm{~m}$ with respect to the validation nCM. The height proportions for both $\mathrm{nCM}_{\mathrm{FLV}}$ and $\mathrm{nCM}_{\mathrm{ULV}}$ seem to be reasonable, since street trees in Berlin are generally smaller than in large green areas due to pruning and limiting environmental factors [54]. The $\mathrm{nCM}$ resulting from the weighted DPMF ( $\mathrm{nCM}_{\mathrm{FLV} \text { _II }}$ ) was found to produce better results than the one using the interpolation approach (nCM $\left.\mathrm{FLV}_{\mathrm{I}}\right)$. Incorrect heights within all $\mathrm{nCMs}$ 


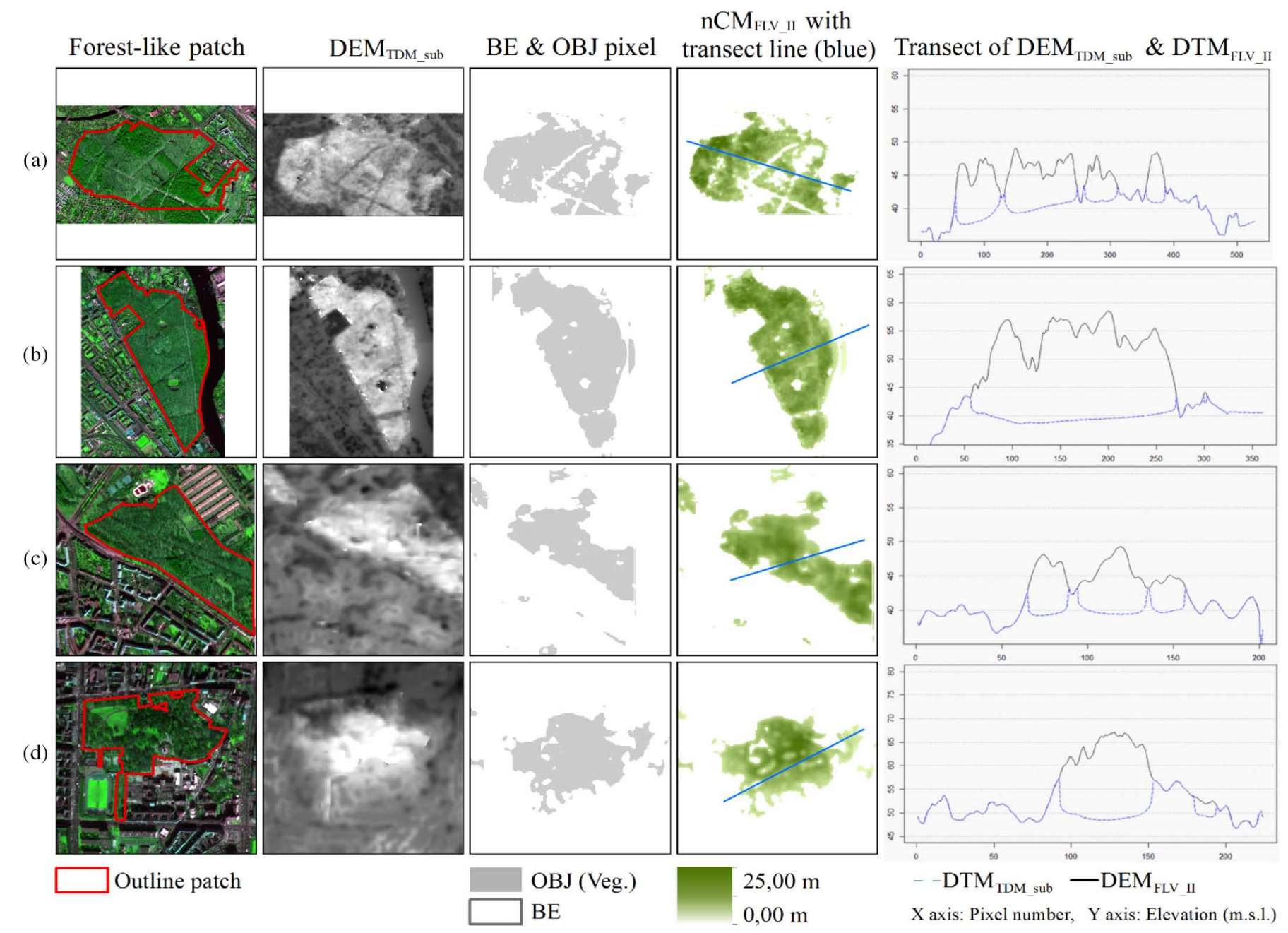

Fig. 6. (a)-(d) Examples of forest-like patches and corresponding $\mathrm{DEM}_{\mathrm{TDM}}$ sub identified BE and OBJ pixels during DPMF, the final nCM $\mathrm{FLV}_{-} \mathrm{II}$, and transects of DEM $\mathrm{TDM}_{\text {_sub }}$ compared to DTM $\mathrm{FLV}_{\mathrm{II}}$ (from left to right).

were caused by overestimations of the DTM and several potential methodological and data-related errors. First of all, the pixel values of the preprocessed DTM were slightly changed during the disaggregation and the following three-point linear interpolation of cells within the DPMF. Especially in areas of urban-like vegetation, edges of objects were smoothed and thus elevations in the nDSM were lowered, which mostly affects rectangular structures, as well as vegetation [55]. Second, even though lowered vegetation heights are improbable because of low penetration rates of the X-band segment [35], a potential disturbance of height values is possible and was proven within an initial test. Therefore, the preprocessed $\mathrm{DEM}_{\mathrm{TDM}}$ with its original spatial resolution was subtracted from the validation DTM to gain an experimental $\mathrm{nCM}$; its mean elevation was calculated to be $12.44 \mathrm{~m}$ (for comparison, $\mathrm{nCM}_{\mathrm{Val}}$ : $13.55 \mathrm{~m}$ ), which prove disturbed height values in the original iDEM. Such potential errors will be likely reduced in the final global DEM that consists of more than one coverage and will be available in the upcoming years [33]. Further on, for urban-like vegetation, the validity of results had to be restricted since the close proximity between vegetation and neighboring objects likely caused mixed pixels with different heights [56]. This effect can be
TABLE IV

Descriptive Statistics AND RMSE For FLV Height Models $\left(\mathrm{DTM}_{\mathrm{FLV}} \mathrm{I}, \mathrm{DTM}_{\mathrm{FLV}} \mathrm{II}, \mathrm{nCM}_{\mathrm{FLV}} \mathrm{I}, \mathrm{nCM}_{\mathrm{FLV}} \mathrm{I}\right)$ AND VALIDATION HeIGHT Models $\left(\mathrm{DTM}_{\text {Val }}, \mathrm{nCM}_{\text {Val }}\right)$

\begin{tabular}{c|c|c|c|c|c|c}
\hline Height & Mean & Min. & Max. & MAE & ME & RMSE \\
\hline \multicolumn{7}{c}{ DTM } \\
\hline DTM $_{\text {FLV I }}$ & 42.34 & 26.12 & 59.68 & 5.34 & 5.08 & 5.74 \\
DTM $_{\text {FLV II }}$ & 40.37 & 30.43 & 69.67 & 3.87 & 3.08 & 4.22 \\
DTM $_{\text {Val }}$ & 37.19 & 31.16 & 67.82 & - & - & - \\
\hline \multicolumn{7}{c}{$\mathrm{nCM}$} \\
\hline nCM $_{\text {FLV I }}$ & 7.83 & 4.95 & 23.78 & 8.67 & -8.38 & 9.99 \\
nCM $_{\text {FLV II }}$ & 9.16 & 0.001 & 29.75 & 5.88 & 4.78 & 6.81 \\
nCM $_{\text {Val }}$ & 13.55 & 2.10 & 33.53 & - & - & - \\
\hline
\end{tabular}

counteracted by the use of a high-resolution DEM with a spatial resolution of $6 \mathrm{~m}$ for selected areas, which will be available in the upcoming years upon request [33]. 
Overall, the present findings suggest that it is possible to derive DTMs and subsequently nCMs for various urban vegetation types with appropriate results. The final nCMs correctly represent the relative heights of urban- and forest-like vegetation; however, the absolute values demonstrate the need for future research on DTM assessment, especially for vegetation in urban-like conditions. By overcoming the drawbacks related to terrain assessment, the nCMs for both types can be improved. Moreover, better results will likely be achieved through the application of the final DEM, provided in the upcoming years.

\section{CONCLUSION}

In this paper, an iDEM of the TanDEM-X mission was used for the first time to derive nCMs for urban vegetation exploring a novel procedure. The entire workflow was based on the principles of mathematical morphology. Tailored approaches were proposed for areas including urban-like and forest-like vegetation, respectively, for a typical urban area in the city of Berlin, Germany. An nCM for urban-like vegetation could be assessed using an iterative identification of bare earth pixels by applying a novel DPMF with different thresholds, sizes of structuring elements, and image filters; for forest-like vegetation, a weighted DPMF was found to produce better results than a tested interpolation method. The derived $\mathrm{nCM}$ for typical urban vegetation contained approximately half $(4.35 \mathrm{~m})$, and the $\mathrm{nCM}$ for forest-like vegetation approximately two-thirds $(9.16 \mathrm{~m})$ of the mean elevation in the validation data. Overall, this outcome is very promising and demonstrates the usability of the TanDEM-X DEM for vegetation-related assessments. The weighted DPMF proved especially robust for filtering forest-like vegetation, and its outcome can be enhanced by improving the results for the DTM for urban-like vegetation. The approach is meant to be transferred to other regions and can be conducted with different higher resolution vegetation data. Multispectral QuickBird, Rapideye, and future Sentinel-2 data are promising for this purpose, since their large spatial coverage and spatial resolution favor transferability [57], [58]. The outcome of such studies could be used to automatically assess urban vegetation volume and height classes, which is needed as a basis for various ecosystem services or disservice studies on a large, comparative scale.

\section{ACKNOWLEDGMENT}

The authors would like to thank the German Aerospace Center (DLR) for the provision of intermediate TanDEM-X data, and the Senate Administration of Berlin for providing the additional data products. Moreover, we thank the anonymous reviewers for their very helpful comments on an earlier version of the manuscript.

\section{REFERENCES}

[1] P. Bolund and S. Hunhammer, "Ecosystem services in urban areas," Ecol. Econ., vol. 29, pp. 293-301, 1999.
[2] C. Liu and X. Li, "Carbon storage and sequestration by urban forests in Shenyang, China," Urban For. Urban Green., vol. 11, pp. 121-128, 2012.

[3] D. J. Nowak, "Atmospheric carbon reduction by urban trees," J. Environ. Manage., vol. 37, pp. 207-217, 1992.

[4] J. Yang, J. McBride, J. Zhou, and Z. Sun, "The urban forest in Beijing and its role in air pollution reduction," Urban For. Urban Green., vol. 3, pp. 65-78, 2005.

[5] C. L. Brack, "Pollution mitigation and carbon sequestration by an urban forest," Environ. Pollut., vol. 116, pp. 195-200, 2002.

[6] G. D. Jenerette, S. L. Harlan, W. L. Stefanov, and C. A. Martin, "Ecosystem services and urban heat riskscape moderation: Water, green spaces, and social inequality in Phoenix, USA," Ecol. Appl., vol. 21, pp. 2637-2651, 2011.

[7] F. Lindberg and C. S. B. Grimmond, "The influence of vegetation and building morphology on shadow patterns and mean radiant temperatures in urban areas: model development and evaluation," Theor. Appl. Climatol., vol. 105, pp. 311-323, 2011.

[8] Y. Y. Cui and B. de Foy, "Seasonal variations of the urban heat Island at the surface and the near-surface and reductions due to urban vegetation in Mexico City," J. Appl. Meteorol. Climatol., vol. 51, pp. 855-868, May 2012.

[9] Q. H. Weng, U. Rajasekar, and X. F. Hu, "Modeling urban heat Islands and their relationship with impervious surface and vegetation abundance by using ASTER images," IEEE Trans. Geosci. Remote Sens., vol. 49, no. 10, pp. 4080-4089, Oct. 2011.

[10] R. E. Dales, S. Cakmak, S. Judek, and F. Coates, "Tree pollen and hospitalization for asthma in urban Canada," Int. Arch. Allergy Immunol., vol. 146, pp. 241-247, 2008

[11] G. S. Lovasi et al., "Urban tree canopy and asthma, wheeze, rhinitis, and allergic sensitization to tree pollen in a New York City Birth Cohort," Environ. Health Perspect., vol. 121, pp. 494-500, Apr. 2013.

[12] F. J. Escobedo, T. Kroeger, and J. E. Wagner, "Urban forests and pollution mitigation: Analyzing ecosystem services and disservices," Environ. Pollut., vol. 159, pp. 2078-2087, 2011.

[13] J. Ostberg, M. Martinsson, O. Stal, and A. M. Fransson, "Risk of root intrusion by tree and shrub species into sewer pipes in Swedish urban areas," Urban For. Urban Green., vol. 11, pp. 65-71, 2012.

[14] D. Nowak and J. Dwyer, "Understanding the benefits and costs of urban forest ecosystems," in Urban and Community Forestry in the Northeast, J. Kuser, Ed. New York, NY, USA: Springer, 2007, pp. 25-46.

[15] E. Casper, Geodatenmanagement in der Berliner Verwaltung-Amtliches 3D Stadtmodell für Berlin. Berlin, Germany: Berlin Partner GmbH, 2008.

[16] T. Kolbe, "CityGML-Ein Standard für virtuelle 3D-Stadtmodelle," presented at the REFINA-Workshop, Potsdam, Germany, 2008.

[17] D. J. Nowak and E. J. Greenfield, "Tree and impervious cover change in U.S," Urban For. Urban Green., vol. 11, pp. 21-30, 2012.

[18] M. W. Strohbach and D. Haase, "Above-ground carbon storage by urban trees in Leipzig, Germany: Analysis of patterns in a European city," Landscape Urban Plann., vol. 104, pp. 95-104, Jan. 2012.

[19] J. Schreyer, J. Tigges, T. Lakes, and G. Churkina, "Using airborne LiDAR and quickbird data for modelling urban tree carbon storage and its distribution-A Case Study of Berlin," Remote Sens., vol. 6, pp. 10636-10655, 2014.

[20] B. Hoefle, M. Hollaus, and J. Hagenauer, "Urban vegetation detection using radiometrically calibrated small-footprint full-waveform airborne LiDAR data," ISPRS J. Photogramm. Remote Sens., vol. 67, pp. 134-147, Jan. 2012

[21] I. Colomina and P. Molina, "Unmanned aerial systems for photogrammetry and remote sensing: A review," ISPRS J. Photogramm. Remote Sens., vol. 92, pp. 79-97, Jun. 2014

[22] Q. L. Feng, J. T. Liu, and J. H. Gong, "UAV remote sensing for urban vegetation mapping using random forest and texture analysis," Remote Sens., vol. 7, pp. 1074-1094, Jan. 2015.

[23] J. R. Jensen, Remote Sensing of the Environment: An Earth Resource Perspective, 2nd ed. Englewood Cliffs, NJ, USA: Prentice Hall, 2000.

[24] R. L. Jordan et al., "Shuttle radar topography mapper (SRTM)," in Proc. SPIE-Int Soc. Opt. Eng., Bellingham, WA, USA, 1996, vol. 2958, pp. $412-422$.

[25] G. Krieger et al., "TanDEM-X: A satellite formation for high-resolution SAR interferometry," IEEE Trans. Geosci. Remote Sens., vol. 45, no. 11, pp. 3317-3341, Nov. 2007.

[26] J. Serra, Image Analysis and Mathematical Morphology. New York, NY, USA: Academic, 1984.

[27] X. Meng, N. Currit, and K. Zhao, "Ground filtering algorithms for airborne LiDAR data: A review of critical issues," Remote Sens., vol. 2, pp. 833-860, 2010. 
[28] C. Geiß, M. Wurm, M. Breunig, A. Felbier, and H. Taubenböck, "Normalization of TanDEM-X DSM data in urban environments with morphological filters," IEEE Trans. Geosci. Remote Sens., vol. 53, no. 8, pp. 4348-4362, Aug. 2015.

[29] M. Marconcini, D. Marmanis, T. Esch, and A. Felbier, "A novel method for building height estimation using TanDEM-X data," presented at the 2014 IEEE Int. Geosci. Remote Sens. Symp. (IGARSS), Quebec City, QC, Canada, 2014.

[30] A. Berlin-Brandenburg, Statistical Yearbook Berlin-Brandenburg 2013 [Statistisches Jahrbuch 2013 Berlin-Brandenburg. Potsdam, Germany: Amt für Statistik Berlin-Brandenburg, 2013.

[31] S. a. o. B. (SenStadt), Environmental atlas of Berlin-05. Biotopes. Berlin, Germany: Senate Administration of Berlin, 2012.

[32] S. a. o. B. (SenStadt), Environmental Atlas of Berlin-Structure Types. Berlin, Germany: Senate Administration of Berlin, 2014.

[33] G. A. C. (DLR), "TanDEM-X ground segment-DEM products specification document," Earth Observation Center (EOC), Oberpfaffenhofen, Germany, Tech. Rep. Public Document TD-GS-PS-0021, 2013.

[34] A. M. Poznanska, "Determination of building and vegetation heights in the city of Berlin [Bestimmung von Gebäude- und Vegetationshöhen im Berliner Stadtgebiet],” Deutsches Zentrum für Luft- und Raumfahrt (DLR e. V.) Abteilung Sensorkonzepte und Anwendungen am Institut für Optische Sensorsysteme, Berlin, Germany, 2013.

[35] G. A. C. (DLR), (2014). TanDEM-X-Application and Use [Tandem-X - Anwendung und Nutzung] [Online]. Available: http://www.dlr.de/dlr/ desktopdefault.aspx/tabid-10391/577_read-701/\#gallery/346

[36] B. f. K. u. G. (BKG), German combined QuasiGeoid (GCG) 2011, Leipzig, Germany: Bundesamt für Kartographie und Geodäsie, 2012.

[37] F. Wang, Quantitative Methods and Applications in GIS, 1st ed. Boca Raton, FL, USA: CRC Press, 2006.

[38] M. M. Breunig and H.-P. Kriegel, "LOF: Identifying density-based local outliers," in Proc. SIGMOD Rec., 2000, vol. 29, pp. 93-104.

[39] U. S. G. S. (USGA), "Digital elevation models (DEM)-Data users guide," in Earth Science Information Center and U. S. G. Survey, 3rd ed., Reston, Virginia: United States Geological Survey, 1993.

[40] R. C. Team, R: A Language and Environment for Statistical Computing. Vienna, Austria: R Foundation for Statistical Computing, 2014.

[41] E. V. I. Solutions, ENvironment for Visualizing Images (ENVI). Boulder, CO, USA: Exelis Visual Information Solutions, 2013, vol. 5.0.

[42] P. Kupidura and P. Koza, "Radar imagery filtering with use of the mathematical morphology operations," Polish J. Environ. Stud., vol. 17, pp. 31-35, 2008.

[43] J. J. Zhang, S. H. Chen, D. Whitmann, M.-L. Shyu, J. Yan, and C. Zhang, "A progressive morphological filter for removing nonground measurements from airborne LIDAR data" IEEE Trans. Geosci. Remote Sens., vol. 41, no, 4, pp. 872-882, Apr. 2003.

[44] P. R. Smith, "Bilinear interpolation of digital images," Ultramicroscopy, vol. 6, pp. 201-204, 1981.

[45] D. Shepard, "A two-dimensional interpolation function for irregularlyspaced data," presented at the 23rd ACM National Conf., New York, NY, USA, 1968.

[46] E. M. Eliason and A. S. McEwen, "Adaptive box filters for removal of random noise from digital images," Photogramm. Eng. Remote Sens., vol. 56, pp. 453-458, 1990.

[47] T. M. Lillesand and R. W. Kiefer, Remote Sensing and Image Interpretation, 5th ed. Hoboken, NJ, USA: Wiley, 2004.

[48] R. L. Czaplewski, "Variance approximations for assessments of classification accuracy," U.S. Dept. Agric. For. Serv. Rocky Mountain For. Range Exp. Station, Fort Collins, CO, USA, Tech. Rep. RM-316, 1994.

[49] M. Jakubowski, W. Li, Q. Guo, and M. Kelly, "Delineating individual trees from lidar data: A comparison of vector- and raster-based segmentation approaches," Remote Sens., vol. 5, pp. 4163-4186, 2013.

[50] M. Larsen, M. Eriksson, X. Descombes, G. Perrin, T. Brandtberg, and F. A. Gougeon, "Comparison of six individual tree crown detection algorithms evaluated under varying forest conditions," Int. J. Remote Sens., vol. 32, pp. 5827-5852, 2011.

[51] A. Rasanen, A. Rusanen, M. Kuitunen, and A. Lensu, "What makes segmentation good? A case study in boreal forest habitat mapping," Int. J. Remote Sens., vol. 34, pp. 8603-8627, Dec. 2013.

[52] B. Romstad and B. Etzelmuller, "Mean-curvature watersheds: A simple method for segmentation of a digital elevation model into terrain units," Geomorphology, vol. 139, pp. 293-302, Feb. 2012.

[53] J. K. Liu, D. S. Liu, and D. Alsdorf, "Extracting ground-level DEM from SRTM DEM in forest environments based on mathematical morphology," IEEE Trans. Geosci. Remote Sens., vol. 52, no. 10, pp. 6333-6340, Oct. 2014.
[54] H. Sukopp, Urban Ecologie-The Case of Berlin [Stadtökologie-Das Beispiel Berlin], H. Sukopp, Ed., Berlin, Germany. 1990.

[55] F. Arif and M. Akbar, and IEEE, Resampling Air Borne Sensed Data Using Bilinear Interpolation Algorithm. New York, NY, USA: IEEE, 2005.

[56] T. Lakes, P. Hostert, B. Kleinschmit, S. Lauf, and J. Tigges, "Remote sensing and spatial modelling of the urban environment," in Perspectives in Urban Ecology-Ecosystems and Interactions between Humans and Nature in the Metropolis of Berlin, W. Endlicher, Ed. New York, NY, USA: Springer, 2011, pp. 231-259.

[57] J. Tigges, T. Lakes, and P. Hostert, "Urban vegetation classification: Benefits of multitemporal RapidEye satellite data," Remote Sens. Environ., vol. 136, pp. 66-75, 2013.

[58] Y. H. Ke and L. J. Quackenbush, "A review of methods for automatic individual tree-crown detection and delineation from passive remote sensing," Int. J. Remote Sens., vol. 32, pp. 4725-4747, 2011.

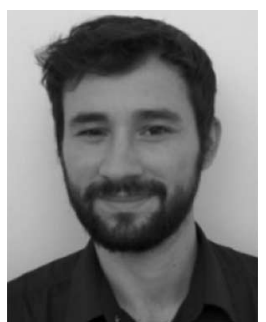

Johannes Schreyer received the B.Sc. degree in applied geography from the RWTH Aachen University, Aachen, Germany, in 2009 and the M.Sc. degree in physical geography of large cities from the Humboldt-Universität zu Berlin, Berlin, Germany, and the University Paris Diderot, Paris, France, in 2012.

Since 2013, he has been a Doctoral Researcher with the Geoinformation Science Laboratory, Department of Geography, Humboldt-Universität zu Berlin, Berlin, Germany. His research interests include application of (high resolution) remote sensing and integration of additional data on spatial analyses of human-environment systems, and urban vegetation assessment using remote sensing data.

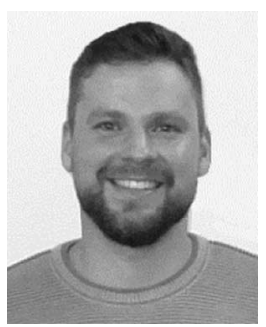

Christian Geiß (M'15) received the M.Sc. degree in applied geoinformatics from Paris Lodron University of Salzburg, Salzburg, Austria, in 2010, and the Ph.D. (Dr.rer.nat) degree in Geoinformatics from the Humboldt University of Berlin, Berlin, Germany, in 2014

Since 2010, he has been with German Remote Sensing Data Center (DFD), German Aerospace Center (DLR), Weßling, Germany. His research interests include renewable energy, earthquake risk assessment, methods for remote sensing data processing, techniques of multimodal remote sensing, machine learning, and pattern recognition, specifically applied to the field of natural hazard risk research.

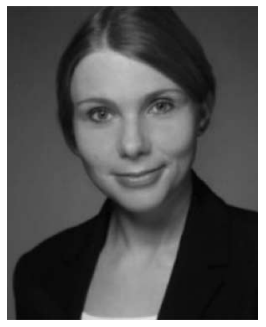

Tobia Lakes received the degree in geography from the Universities of Bonn, Duisburg, and Belfast; in Bonn, Germany; Essen, Germany; and Belfast, U.K., respectively, the Diploma degree in geography from the University of Bonn in 2001, and the Ph.D. (Dr.-Ing.) degree in geoinformation science and environmental planning from the Technische Universität Berlin, Berlin, Germany, in 2006.

Between 2007 and 2015 she was an Asisstant Professor of Geoinformatics and is now a full professor with the Geography Department HumboldtUniversität zu Berlin, Berlin, Germany. She has contributed to several research projects on remote-sensing data and spatial modeling. Her research interests include integration of remote-sensing data with additional data to model the human-environment system in a spatially explicit way, urban areas and land use change. 